\title{
Policy Effect of the Public Health Clinic Closure and Consolidation Policies on All the Preventative Practices Following the Affordable Care Implementation in Louisiana
}

\author{
Anita Feist \\ Department of Public Policy, Southern University and A \& M College, Baton Rouge, LA
}

\begin{abstract}
The purpose of this study is to examine the policy effect of the public health clinic closure and consolidation policies on public health preventive practices in Louisiana. It is observed in the literature that many governments' efforts towards the healthcare market has being failing across different political administrations. This is because the current health care reform, public health clinics closures and policy consolidations following the implementation of the affordable care act seems to be disappointing in the state of Louisiana. Currently, many parishes, are battling with low health care professional's availability, and high prevalence of poor health outcomes (i.e. high spread of STDs, high cancer spread, low accessibility to healthcare, and several communicable diseases) making all the public health interventions programs or initiatives look bad in the face of the policy reforms. However, it is not clear whether the policy consolidation and public health clinics closures are the causal factors to the high spread of diseases and health disparities across the parishes. As a result, this particular study used paired t-test and secondary source of data from the Department of Health and Hospitals and Integrated Public Use Microdata Series USA (IPUMS-USA) spanning from 2008 to 2019 to examine the problem. The study finds that the average Gonorrhea infection rate, and P\&S Syphilis infection rate between 2014 and 2019 is greater than the average infection rate before the closure of the public health clinics (2008 and 2013). Above all, the study establishes that there is a strong evidence of significant difference in the following: (a) access to healthcare, (b) Sexually-Transmitted Disease (STD) Screening preventative practices, and (c) the participation of Breast Cancer Screening preventative practices resulting from the different periods of policy implementation in relation to public health clinic closures. Therefore, the study recommends that all the closures of the public health clinics needs to be reopen to ensure a greater access to healthcare and healthy population.
\end{abstract}

Keywords: Healthcare, ACA, Clinic, Policy, healthcare, Preventive, Screening, and STDs.

DOI: $10.7176 / \mathrm{PPAR} / 10-11-05$

Publication date: November $30^{\text {th }} 2020$

\section{INTRODUCTION}

The state of Louisiana has experienced tremendous closures of public health clinics between 2014/2015 and 2016/2017 fiscal years and has continued up to date by following the federal healthcare reforms policies (or policy consolidations). Meanwhile, these federal health care reforms have shriveled the expansion of eligibility thereby limiting accessibility of healthcare, depriving nearly half the Louisiana state's population to receive health care through Medicaid (Census Bureau's Current Population Survey, 2014). Among all 50 states, Louisiana has the toughest income eligibility for Medicaid, with enrollment expected to increase to between 366,318 and 507,952 recipients by 2019 (DHH, 2014). In an effort to increase overall health outcomes and prepare the state for the major changes in health care delivery of the Affordable Care Health Reform Acts, the Department of Health and Hospital (DHH) proposed transforming Medicaid from the current fee-for-service system to coordinated care Networks (CCNs) in order to expand access to healthcare facilities. In addition to the use of Electronic Health Record Systems, DHH proposed that transitioning from the current fee-for-service Medicaid program to a system that more effectively coordinates' health care will lead to better access, more choices, and improved health for patients (DHH, 2014).

Louisiana parishes such as East Baton Rouge, Orleans, and Jefferson had the most Medicaid Enrollees during 2010 and 2014. Some parishes, with low health care professionals available, were recognized as having poor health outcomes. They have been several attempts in Louisiana to address issues that are associated with the shortage of health professionals available, yet the state still continues to have an unequal distribution of primary care physicians. According to the Federal Bureau of Primary Health Care, one in four Louisiana residents' lives in an area that has been federally designated as a primary care shortage area. Kaiser Family Foundation based estimates on the Census Bureau's Current Population Survey (2014) and estimates show that there is one primary care physician for every 1,937 people in Louisiana. Normally, this number would be adequate to meet the primary health care needs of Louisiana's residents if these providers were evenly distributed throughout the state and accepted all patients regardless of ability to pay. However, this is not the case as is evident by the estimates made by the, the Federal Bureau of Primary Health Care. They estimate that, as of May 2004, 81 percent of the primary care physicians who are practicing in the state are located in one of 11 urban parishes. There is one primary care 
physician for every 1,408 urban residents, unfortunately for the 41 percent of Louisiana's residents who live in rural areas, this means that there is only one physician for every 4,187 of them. This constitutes a severe shortage in rural areas across the state, and within parishes, some areas are more underserved than others.

The department of Health and Hospital's re-appropriation of Medicaid expenditures, in its adjustments to changes within the national healthcare system, has put Louisiana in an urgent need of change regarding the quality of care and other resources that are provided. There is a severe need to improve the health outcomes of the state's overall population. Historically, Louisiana has been shown to have poor health outcomes in general and, more specifically, very poor health outcomes with regard to its vulnerable populations (DHH, 2017). According to America's Health rankings for 2015, Louisiana's ranked $50^{\text {th }}$ out of 50 states regarding health outcomes, even greater than the District of Columbia, which ranked last in 2010. The report also cites high infectious diseases at 23.8 per 100,000, high rates of preventable hospitalizations, and high rates of cancer deaths at 220.1 deaths per 100,000. Additionally, a 2009 Louisiana State Scorecard, published by the Commonwealth Fund, shows the state ranked $49^{\text {th }}$ overall and $45^{\text {th }}$ in prevention treatments (Cantor, 2010; United Health Foundation, 2010). This report also cited both high incidents of substance abuse and high rates of mental illness. The purpose of this study is to better understand changes in the public health units' data in Louisiana state parishes resulting from the public health clinic closure and consolidation policies on all the preventative practices.

Ultimately, this will provide insights to policymakers and hence allows for the creation of more adequate policies. As result the study investigate the following research questions: (a) Why do clinic closure and consolidation policies matter to Public Health Unit in Louisiana? And (b) Is there any difference in the public health units' data on breast cancer screening, STD screening, and access to healthcare based on clinic closure and consolidation policies? The researcher aims to examine factors that determine whether an individual receives health care and to determine an individual's access to health care pre and post-implementation of the Affordable Care Act. Policy makers can utilize this research in evaluating current policies and programs as well as by developing and implementing a plan to reduce and eliminate existing and future barriers in obtaining health care and in turn achieve better health outcomes. As the United States moves toward a more neoliberal agenda that advocates for smaller government, regionalization, and privatization of industry and public services; trends affecting access, quality, outcomes, and costs must be monitored. A growing body of research suggests that in areas where public hospitals have been privatized, care for the uninsured declined (Waiztkin, 2005). This research focuses on measuring the immediate impact of specific policy changes on preventative health care in parishes throughout Louisiana.

\section{LITERATURE}

\section{Public Health Diseases}

Chlamydia

In 2018, a total of 1,758,668 cases of Chlamydia trachomatis infection were reported to the CDC, making it the most common notifiable condition in the United States. The case count number corresponds to a rate of 539.9 cases per 100,000 population, an increase of $2.9 \%$ compared with the rate in 2017. During 2017-2018, rates of reported chlamydia increased among both males and females, in all regions of the United States, and among all racial/Hispanic ethnicity groups. Rates of reported chlamydia are highest among adolescents and young adults. In 2018, almost two-thirds of all reported chlamydia cases were among persons aged 15-24 years. Among females aged 15-24 years, the population targeted for chlamydia screening, the overall rate of reported cases of chlamydia was 3,693.6 cases per 100,000 females, an increase of $1.0 \%$ from 2017 and of $11.8 \%$ from 2014 .

Although rates of reported cases among men are generally lower than rates among women, reflecting the larger number of women screened for this infection, rates among men increased 37.8\% during 2014-2018. The increase in rates among men may reflect an increased number of men, including gay, bisexual, and other men who have sex with men (MSM) being tested and diagnosed with a chlamydial infection due to increased availability of urine testing and extragenital screening.

\section{Gonorrhea}

In 2018 , a total of 583,405 cases of gonorrhea were reported to the CDC, making it the second most common notifiable condition in the United States. Rates of reported gonorrhea have increased to $82.6 \%$ since the historic low in 2009. During 2017-2018, the overall rate of reported gonorrhea increased 5.0\%, and rates increased among both males and females, in all regions of the United States, and among all racial/Hispanic ethnicity groups. Since 2013, the rate of reported gonorrhea has been higher among men compared to women. Among men, the rate of reported gonorrhea increased 6.0\% during 2017-2018 and 78.7\% during 2014-2018, while rates among women increased 3.6\% during 2017-2018 and 45.2\% during 2014-2018. The higher case rate among men and the magnitude of recent increases suggests either increased transmission, increased case ascertainment (e.g., through increased extra-genital screening among MSM), or both.

The concurrent increase in cases reported among women suggests parallel increases in heterosexual 
transmission, increased screening among women, or both.

Gonorrhea can quickly develop resistance to antibiotics used to treat infection, and in 2018, more than half of all infections were estimated to be resistant to at least one antibiotic. Since 2009, almost all circulating strains in the United States, based on gonococcal isolates collected through sentinel surveillance, remain susceptible to ceftriaxone, the primary treatment for gonorrhea; only $0.2 \%$ of isolates displayed elevated ceftriaxone minimum inhibitory concentrations in 2018. Continued monitoring of susceptibility patterns to antibiotics is critical information for the treatment gonorrhea guidelines.

\section{Syphilis}

In 2018, 115,045 cases of all stages of syphilis, were reported, including 35,063 cases of primary and secondary (P\&S) syphilis, the most infectious stages of the disease. Since reaching a historic low in 2000 and 2001, the rate of P\&S syphilis has increased almost every year, increasing 14.9\% during 2017-2018. Rates increased among both males and females, in all regions of the United States, and among all racial/Hispanic ethnicity groups. Since 2000, rates of P\&S syphilis have increased among men, primarily attributable to increases in cases among MSM. Similar to past years, in 2018, MSM accounted for the majority (53.5\%) of all reported cases of P\&S syphilis and, of these, $41.6 \%$ were known to be living with diagnosed HIV. Although rates of P\&S syphilis are lower among women, rates have increased substantially in recent years, increasing 30.4\% during 2017-2018 and $172.7 \%$ during 2014-2018. This suggests a rapidly growing heterosexual epidemic.

The 2013 rate of congenital syphilis (9.2 cases per 100,000 live births) marked the first increase in congenital syphilis since 2008. Since 2013, the rate of congenital syphilis has increased each year. In 2018, 1,306 cases of congenital syphilis were reported. Although the majority of cases were reported from a few states, 41 states reported at least one case of congenital syphilis in 2018. Hence, the national rate of 33.1 cases per 100,000 live births in 2018 represents a $39.7 \%$ increase relative to 2017 and a $185.3 \%$ increase relative to 2014. During 20172018 the number of syphilitic stillbirths increased (from 64 to 78 stillbirths), as did the number of congenital syphilis related infant deaths (from 13 to 16 deaths).

Furthermore, a 2015 Louisiana State Scorecard by the Commonwealth Fund showed that the state ranked $48^{\text {th }}$ overall in preventive healthcare treatment (Foubister, 2013). In 2014, expenditures for health care services constituted nearly $18 \%$ of the United States Gross Domestic Product and, in some way, affected all Americans (National Health Statistics Group, 2014). Expenditures on health care in the United States surpassed \$2.3 trillion in 2008, which was more than eight times the \$253 billion in 1980 (Kimbuende, Ranji,Lundy,\& Salganicoff, 2010). Investments in healthcare can benefit all U.S citizens; however, due to the current economic conditions and the recent expansion of healthcare, systems established to finance healthcare have been strained. Specifically, there have been limits put on public insurance programs, such as Medicaid and Medicare; however, private health insurance has accounted for the largest National Health Expenditures (Kaiser Family Foundation and Health Research and Educational Trust, 2014).

Clearly, insurance is a major factor in how changes in healthcare affect the general population. According to the World Health Organization (WHO) social determinants of health such as the conditions in which a person is born into, grows, lives and works along with a person's age are the factors that are responsible for health inequities. However, most research conducted focused on sickness and disease as identifiable factors that contribute to health disparities and in essence health inequity, yet the determinants established by the WHO are often overlooked in research.

Therefore, one's ability to access health insurance coverage is the first step in eliminating disparities and inequity in health. Several changes have and will continue to be implemented, due to the passage of the Affordable Health Care Acts (2010). Some of these changes specifically deal with acts affecting those individuals who are either not insured or underinsured. Because Medicaid is a federal program that is paid for through state matching funds, when state revenues are down these matching funds can become nearly nonexistent. As more and more of the state's budget becomes constrained due to the current economic recession, they look for ways to make major cost cutting measures that includes a reduction in benefits, eligibility, and payment to providers as they now have the right to form acts like (COBRA) the Consolidated Omnibus Budget Reconciliation Act.

Policy analysis is a useful way of examining how changes in expenditures or current political ideologies can affect the population that selected its leaders, make important decisions with regard to their health, well-being, environment, and economy.

The purpose of this dissertation is to review the implementation method used and to analyze the effects that occur as a result of the policy change. More specifically, this research focuses on identifying the short-term impacts on certain preventive health care indicators used throughout Louisiana's public health clinics by parishes. The focus is on the main health indicators around STDs, routine health screenings rendered, and visits to the units because these are the main services or encounters that are expected to decrease due to fewer hours of service post consolidation in the parishes throughout Louisiana. Since Public Health Clinics primarily deal with preventive health measures, the researcher asserts that it would be appropriate to show health indicators that are reflective of 
preventive services.

\section{Previous Policies that Affect Clinic Closures and or Consolidation}

Since this dissertation is a policy analysis, it is important to mention policies that were put in place to initiate the movement of health services to the private sector. On April 7, 1986, President Ronald Reagan signed into law an omnibus budget law that included the EMTALA legislation. Congress passed EMTALA, known as the patient anti-dumping law, in response to national outrage over a surge in community hospitals transferring unstable emergency patients largely for financial reasons. The Emergency Medical Treatment and Active Labor Act (MTALA), part of the Consolidated Omnibus Budget Reconciliation Act (COBRA), passed by Congress in 1986, was the first of such policies to be set in place. According to the EMTALA anyone utilizing emergency room facilities regardless of status must at least be stabilized. But the costs are passed to private insurers through cost shifting, higher fees or through higher taxes (Ayamian, Wessman, Schneider, Ginsburg, \&Zaslavsky, 2000). These two acts substantially changed service delivery in public health clinics. Each act is discussed in more detail further on in this study, with citations regarding economic issues and hospital closures.

Another act shown to have had a part in the delivery of healthcare to the vulnerable populations is the Health Centers Consolidation Act of 1996. Locally, this act made a number of changes to the delivery of health care (Mosser, Karp, \& Rabson, 2006). It both established a new federal loan guarantee program to support the development and operation of managed care networks (the main theme of DHH's movement away from fee-forservice) and consolidated/reauthorized four federal health primary care and prevention programs: community health centers, migrant health centers, health care for the homeless, and health care for residents of public housing programs (Mosser, Karp, \& Rabson, 2006). Initially, its theory was that by giving communities the power to design and develop their own local solutions to health problems, the health status of the nation's medically-underserved, low-income populations will improve (Mosser, Karp, \& Rabson, 2006).

Universal health insurance became a large part of William Clinton (1993-2001) presidency platform. After taking office, Clinton appointed Hilary Clinton to lead a health care task force whose mission was to develop a comprehensive healthcare reform proposal. 34 committees were named part of the task force. In November of 1993 the American Health Security Act bill was presented to congress (Altman \& Shactman, 2011; Taylor, 2014). Despite the bill's principle goal of establishing a system of health insurance coverage that would be provided by employers through private insurers over seen by regional health alliances coordinated by each state, opposition was received from both the health care and health insurance industries (Taylor, 2014). The bill died in congress leading to the 1994 Republican victories of both houses for the first time since 1950 (Altman \& Shactman, 2011; Taylor, 2014). Although President Clinton was unsuccessful in passing the American Health Security Act he was successful in passing other healthcare reform initiatives. Among these notable reforms were the Health Insurance Portability and Accountability Act of 1996 which was an initiative containing private health insurance reform allowing some Americans to maintain their health insurance after losing or changing their jobs; Medicare Advantage, which allowed Medicaid recipients to receive not only insurance coverage but an expanded list of benefits through subsidized private insurance plans; and the State Children's Health Insurance Program (S-CHIP), which was created to expand health coverage to children in families whose income is too high to qualify for Medicaid but low enough where affording private insurance is impossible (Altman \& Shactman, 2011). Clinton asserted the following with regards to the American Presidency Project of 1996:

As the delivery of health care move toward managed care arrangements, particularly for the Medicaid population, health centers must be able to participate in these arrangements in order to continue to ensure access to health care services for the medically underserved individuals. This caused other clinical entities to be formed that were in direct competition with the local state public health clinics (Altman \& Shactman, 2011). These acts are called Federally Qualified Health Centers (FQHCs). With the addition of both acts, health care delivery had options that it did not have in the past. Overall, depending on what type of structure the state has, there are significant changes being made to both state-funded hospitals and local health clinics (Altman \& Shactman, 2011). These structural differences include states being viewed by the terms stand alone, umbrella, and mixed function. Stand-alone agencies are independent from other agencies and have individual missions. Louisiana falls under a larger umbrella with agencies such as Department of Health and Hospitals. Such states are independent, and other functions besides public health, like Medicaid and insurance regulation, are considered mixed (Trust for America's Health, 2009). California is considered to have a stand-alone structure, because every county in California serves a particular need for that particular area. In contrast, Texas has a mixed structure due to its regulating authority over its counties and its role in administering other larger programs. The differences in structure may affect services because both mixed and standalone entities have more autonomy in making decisions with regard to the public's health. Additionally, umbrella functioning governments must follow the policies of centralized entities, which may not consider local public health issues. This research is only concerned with Louisiana's umbrella functioning structure. This centralized implementation takes place within the Department of Health and Hospitals in Louisiana. Those with the umbrella structure are given directives from top down and generally provided with 
funds from state budgets approved by legislatures.

\section{FHQCs versus State Health Clinics}

Currently in Louisiana there has been a move to push more patients to other health facilities, particularly FQHCs, and in some cases privately owned clinics, to cut state expenditures. FQHCs were found to have served a large portion of the uninsured (See figure). There are some major differences between traditional health clinics and the two aforementioned health facilities. Traditional public health clinics throughout Louisiana, as well as in most states under the umbrella structure, focus entirely on preventative services (American Cancer Society, Facts about Cancer 2011).

Most local health clinics deliver preventive health services, such as Family Planning, STD and pregnancy testing, and some STD and Tuberculosis treatment and follow-up. FQHCs and independently-owned health clinics have both preventive and primary services, making them much more competitive among the local health clinics (American Cancer Society, Facts about Cancer 2011). As more services are cut from state public health facilities, FQHCs and private clinics must make up for those cuts by conducting the activities up themselves (American Cancer Society, Facts about Cancer 2011). With this, there are a few issues that may arise. Not all private practices agree to serve patients who are uninsured or affiliated with Medicaid, due to reimbursement issues and future changes in policies that may affect revenues. Although, Louisiana has kept a relatively stable employment rate, compared to other states, public health care recipients continue to suffer with extreme rates of cancer deaths, and infant mortality. There has been a recent decrease, in the diagnosis of cancer in Louisiana; however, the combined mortality rate for Louisianans with cancer is about $30 \%$ higher than the national average (American Cancer Society, Facts about Cancer 2011).

There are some services that require follow up, which may include investigation by their partners, adherence to medication, and repetitive health education programs that neither institution may offer. These issues are mentioned later on in the report.

In more rural areas, there is no public transportation; therefore, it is very difficult for some individuals to get to the clinics. Thus, the location of the institution may not be the most suitable to serve the population. Neighborhoods are much more spread apart making it hard for FQHCs and private clinics to choose a centralized location. Because metropolitan areas are much more populated, neighborhoods and residents are in relatively close living spaces. This makes it more attractive for FQHCs and private clinics regarding health services to the public. Further, public transportation in the metro areas is much more feasible to market for patients. This is the reason most FQHCs are clustered in metropolitan areas in Louisiana (Health Resources and Services Administration, 2013).

From the researched literature, there were a number of examples that showed negative consequences to the closures of clinics and in broader terms closure of public health institutions, which may include public hospitals. In addition, there have been some pros and cons associated with states shifting from fee-for-service to a comprehensive care system or managed care.

\section{Fee-for-Service versus Managed Care}

Because the closures and consolidations of the public health units are a result of the state preparing to shift Medicaid services for the public to private entities, this research explores the differences between fee-for-service and managed care.

\section{Fee-for-Service}

Generally, fee-for-service means what it says, for every specific service there is a fee. Under this method, health care providers, physicians, hospitals, and clinics, get paid for each service they perform. Under this system there is no limit to tests or treatments, and the providers have no limitations on their decisions to treat patients. One of the few advantages of this system is that the patients have all treatment methods at his/her disposal, based on the recommendations of the health care provider. Additionally, with fee-for-service, patients may see whichever physician they like, given that they accept Medicaid (Blavin et al., 2018). However, there are some major drawbacks with fee-for-service programs.

First, it is up to the healthcare provider to decide what prices are charged for every visit. This may be detrimental for the patient, because some choices for care may not be covered by the individual's insurance. Secondly, some form of payment must be made after service. For Medicaid beneficiaries and patients who come to public health clinics, this is not usually the case. There is a sliding scale based on the income that is used at the public health clinics, but by law, public health clinics cannot turn patients away based on their inability to pay (Blavin et al., 2018).

There are advantages for the physicians and clinics in the fee-for-service system, because providers may choose what tests are needed and have no limits on what tests or diagnoses can be done. This is called defensive medicine, wherein the physician or healthcare provider has uncertainty about the appropriate level of care and, 
therefore, has a financial incentive to maximize resources available for treatment or care. This allows them to have tests done that may not necessarily be a benefit to the patient.

\section{Managed Care}

Managed care, on the other hand, gives strong financial incentives for patients to seek a Healthcare provider that is part of the managed care group. Under managed care, there is a periodic check-up method used to follow patients' progress or decline. The primary care physician is paid for by the plan and is given financial incentives if they can show an overall improvement in health outcomes. Regular preventive screening and an entire spectrum of healthcare resources are also covered. Unlike fee-for-service, the managed care group is responsible for a specific group of individuals, in this case, those enrolled in Medicaid. Managed care entities receive a set price per individual enrolled, hence giving an incentive to have more individuals in the system (Dobson et al., 2017).

Regarding the Coordinated Care Networks that DHH is proposing, there are two models. The first model is called the traditional model, which establishes networks of healthcare providers that receive a monthly fee for each enrollee covered (to provide core benefits and services). The second model is called the Enhanced Primary Care Case Management Plan. Provider, the networks under this plan receive a monthly per-member fee to provide "enhanced care management services." (Add citation) This allows opportunities for providers to share in savings that result from care coordination.

\section{Effects of Hospital Closures}

Because of the budget shortfalls, states want to reduce healthcare expenditures. Therefore, as mentioned earlier, they have begun to make cuts in public facilities and push more services to community health centers (CHCs). These are comparable to Federally Qualified Health Centers (FQHCs). There are some disadvantages to clinic or hospital closures that can effect local populations. A survey of 846 federally-funded US CHCs between May and September 2004 found that these CHCs face substantial challenges in recruitment of clinical staff, particularly in rural areas. These research findings are elaborated on further in this dissertation when the researcher explains why some parishes are particular interest, due to their status as Medically-Underserved Populations or Health. Historical analysis of the corporatization of healthcare revealed underdevelopment of those institutions serving the neediest populations due to financial issues caused by COBRA and EMTALA act. White (1978) discusses the pressure on private health care institutions to adhere to more bottom-line approaches, as there is more of a push to divert public capital to private entities.

Evidence from the literature suggests several reasons for hospital closures. Hu et al. (2016) cites underutilization of services by residents, exacting government rules and regulations, the economic climate, and unstable physician care as reasons for hospital closures (Benitez \& Seiber, 2017). Although this dissertation investigates closures and consolidations of the clinic, as opposed to hospitals, all of these reasons play a role in this analysis. Underutilization of public health clinics is the main premise for consolidating clinics. The poor economic climate forces the state to find ways to cut costs, which in turn causes state health policymakers to look at the utilization rates of public health clinics in each parish.

Hospital closings are also due to a change in the funding mechanism of government-sponsored programs. By the 1950s, most Americans had private employment-based insurance that covered hospital care, including most emergency care services (Mamor, 1998). It wasn't until the Great Society legislation, launched by President Lyndon B. Johnson (1964-65), that patient emergency department reimbursement rates increased. Because of Medicaid and Medicare provided coverage for the poor and elderly, this was one of the first changes in healthcare service payments. This legislation was enacted in response to the national poverty rate of $19 \%$ in 1964 . Once these entitlement policies were passed, there was no turning back, and the delivery of emergency healthcare services for those who could not afford it was put into law, and all hospitals with emergency departments had to abide by the aforementioned acts. This was the beginning of the initial strain on public institutions, particularly hospitals.

As more individuals started to use Medicaid and Medicare to pay for healthcare services there was a great strain on state-run public hospitals. In 2010 over 60 patients nationwide that received healthcare services from public hospitals used Medicaid for their insurance or were not insured. Furthermore, $43 \%$ of net public health revenues come from Medicaid recipients or the uninsured (Munoz, 1986). Thomas et al. (2016) showed a more recent example of this type of effect resulting from changes in the payment of government programs. The authors identified a trend in closures of hospitals after the implementation of the Prospective Payment System of Medicare. The combination of individuals using Medicare and Medicaid has a role in how much profit is available to the health unit or hospital.

Other researchers have looked at financial issues related to government programs affecting hospital closures. The most prevalent issue related to financial problems within hospitals is inadequate reimbursement rates for services that were provided. Furthermore, Medicare does not cover as wide a range of healthcare services like Medicaid. Medicaid, in particular, has been a contributor to financial problems (Piore, 1977). Unlike Medicare and Social Security Insurance, federal funding for Medicaid comes from the general budget, not from a dedicated 
trust account in the US Treasury.

Reimbursement rates are based on the number of individuals that qualify for Medicaid, based on their family incomes. Non-U.S. citizens, immigrants, and those who have incomes above the federal poverty line, they must pay for private insurance or pay out of pocket expenses. Payments for services to those who cannot afford insurance drains health institutions, hospitals, and clinics, all of which provide this population group with unreimbursed healthcare services. Medicaid, in many states, has ceilings for care that do not allow for all expenses to be covered, therefore causing the institution to pay everything above the ceiling cost (The Lewin Group, 2006).

\section{Effects of Distance from Health Care Facilities}

Distance to a healthcare facility also plays a major role in the health outcomes of a population. Once a health facility closes, the time it takes to travel to another facility and the convenience of getting to that location affect a patient's willingness to receive services. Increased distance to the closest hospital increases deaths from heart attacks and unintentional injuries (Buchmueller, 2006). In fact, Louisiana has a high rate of individuals dying from unintentional injuries. The distance to a hospital could also affect the utilization of primary preventative care. Using data from a survey of Youth's Child Mother File and the American Hospital Association Hospital Survey Currie (December 1998) found that distance to a hospital has significant effects on the utilization of preventive care among central African American children.

Another study sought to find the influence of distance from residence to the nearest hospital and the likelihood of mortality and hospitalization. Goodman (1997) found that distance to a hospital does exert an important influence on hospitalization rates. Additionally, Hyndman et al. (June 2000) wanted to evaluate longitudinal access to mammography clinics and to find out how relocating clinics can improve global access. The researchers found that GIS modeling can be used to evaluate potential locations for screening clinics, and this may improve access for target populations. However, the authors stated that if the technology is not used to evaluate the placement of these clinics, travel distances maybe longer, and this may affect attendance in the clinics.

\section{Environmental Psyche}

Another effect of hospital closure found in existing literature is its impact on the psyche of the environment in which the hospital serves and those who worked at the respective hospital. Indeed, the baby boom surge will ensure the employment of most, if not all, persons either directly working within the healthcare field or indirectly working within the field. Havlovic (1998) wanted to research the impact of hospital closures on employees. The author found that workers from a site that was closed experienced lower levels of job satisfaction in their new jobs. Furthermore, they suggest planning and coordinating outplacement services in an order that reduces the trauma caused by closures. In another article, Mesch et al. (1999) examined the psychological, physical and attitudinal impacts of the closure of a state hospital (Central State Hospital) on former employees of the worksite.

These authors showed that over time workers did have more positive attitudes and less depression; however, immediately after closure, they reported more workplace conflict, lower incomes, and a more pessimistic outlook on their future.

\section{Vaccination}

A study conducted by the CDC showing the impact of closures on SIDs and another study done at the LA County Department of Health showing the impact of vaccination coverage due to clinic closures are the most relevant studies to this research. The CDC study summarized an investigation on the impact of the Northwest SID clinic closures on STD case reports. The investigation results showed that the clinic closure resulted in a significant decrease in reported syphilis cases in the Northwest area and suggested that, due to this, some residents and partners with syphilis in that area, may not have received proper testing therapy and counseling (CDC MMWR, 1995).

A California study on vaccination coverage in Los Angeles County was conducted to assess the impact of the closures of thirty-four health centers that provided $75 \%$ of the doses of vaccines administered during 1994 . This study found that from the vaccination histories that obtained (for the 205 out of the 244 children enrolled in the study less than six years of age), only 29 (18) of 2-year-olds had received four DTP, three OPV, and one MMR (recommended vaccinations) by 24 months of age (Los Angeles Department of Health Services Acute Communicable Disease Control, 1995). This is another example of how closures of health clinics can have drastic effects on the communities that they serve.

These research articles were the only studies found showing direct impacts from the closing of public health clinics. Other literature consulted focused almost exclusively on the closures of hospitals. Moreover, this type of literature focused on why hospitals closed, impact on patient care, impact on competing for health entities, and ways to possibly prevent closure. This research intends to extend these findings to include small, local health clinics and their ability to impact other hospitals, clinics and the population in which they serve.

A study of rural hospital closures suggest that the trend is continuing and this raises questions regarding the 
impact of the closures on access to health care services in rural communities (Antonisse,2016). Antonisse investigated the factors that contributed to the rural hospital closures and the impact of those closures on access to health care in rural communities. The Kaiser Commission on Medicaid and the Uninsured and the Urban Institute together conducted a case study of three hospital closures that took place in 2015: Mercy Hospital in Independence, Kansas; Parkway Regional Hospital in Fulton, Kentucky and Marlboro Park Hospital in Bennettsville, South Carolina. The hospitals had closed recently, and they were not converted to another type of facility such as urgent care facility following the closure. Additionally, they had been reimbursed by Medicare under the prospective payment system (PPS) through predetermined fixed reimbursement rates, not on a cost basis. The researchers applied these criteria to enhance the understanding of the immediate impacts of complete rural hospital closures on community access to care, and to eliminate the effect of Medicare reimbursement type as a confounding factor in their analysis.

Furthermore, they examined the role of state decisions about whether or not to expand Medicaid to nonelderly adults under $138 \%$ of the federal poverty level under the Affordable Care Act (ACA). They selected two hospital closures that took place in states that did not expand Medicaid (Kansas and South Carolina) and one closure that took place in a Medicaid expansion state (Kentucky). The studies addressed the following research questions: (a) what factors contributed to the hospital closure? (b) How did the closure affect access to care? (c) What were the broader community effects of the closure? And (d) Did the state Medicaid expansion decision make a difference in the closure of the hospital or on the president's ability to access care after the closure?

Their findings concluded that a number of factors contributed to rural hospital closures, including demographics like aging, poverty, and declining populations, hospital finances and overall changes in how care is delivered. This research also revealed that the hospital closures reduced local residents' access to care, led to an outmigration of health care professionals and worsened pre-exiting challenges in obtaining access to specialty care. Although some communities were able to adapt to fill the gaps in primary care post-closure, elderly and lowincome individuals were more likely to face transportation challenges and thus more likely to delay or forgo needed care. Moreover, research shows that a state's decision about Medicaid expansion has an important impact on hospital revenues and access to care, but the sustainability of rural hospitals depends on a broader set of factors (Wishner, Solleveld,2016).

\section{METHODS AND MATERIALS}

The study adopts a case-study type of research design. A case-study enables the researcher to narrow-down a broad concept to a specific concept for the purpose of examination and analysis. In addition, the researcher utilizes a secondary source of data from the Louisiana Department of Health, and the Integrated Public Use Microdata Series USA (IPUMS-USA). All the data variables were measured on interval-ratio scale. As part of the data analysis, the study utilizes paired t-test to compare the public health unit data before the closure and after the closure of the public health clinic following the implementation of the Affordable Care Act. The study further examines the following hypotheses: (a) There is no statistical difference in the participation of Breast Cancer Screening preventative practices based on the public health clinic closure and consolidation policies in Louisiana state parishes (before and after implementation of healthcare reforms). (b) There is no statistical difference in the STD Screening preventative practices based on the clinic closure and consolidation policies in Louisiana state parishes to inform public health policy (before and after implementation of healthcare reforms). And (c) There is no statistical difference in access to healthcare (i.e. those who do not get access to healthcare to see a doctor) based on the clinic closure and consolidation policies in Louisiana state parishes to inform public health policy (before and after implementation of healthcare reforms). The variables used in the study are presented in the table below:

\begin{tabular}{|c|c|}
\hline Variables & Measurements \\
\hline \multicolumn{2}{|l|}{ Dependent Variables } \\
\hline $\begin{array}{l}\text { Prevention screening that takes place } \\
\text { in public health clinics during the } \\
\text { specified time period. }\end{array}$ & $\begin{array}{l}\text { Confirmed screenings that took place at health clinics during a specified } \\
\text { time period. These include breast examinations, pelvic examinations, and } \\
\text { STD test that are given in the clinics throughout each parish. }\end{array}$ \\
\hline \multicolumn{2}{|l|}{ Independent Variables } \\
\hline $\begin{array}{l}\text { Time period before PHC closure and } \\
\text { consolidations policy }\end{array}$ & Years 2008-2013 \\
\hline $\begin{array}{l}\text { Time period during/after PHC closure } \\
\text { and consolidation policy }\end{array}$ & Years 2014-2019 \\
\hline
\end{tabular}




\section{DATA ANALYSIS AND DISCUSSION}

Table 1: Descriptive-Summary Statistics of Estimation Variables

\begin{tabular}{|c|c|c|c|c|c|c|c|c|c|c|c|}
\hline Variables & & $\begin{array}{l}\text { Gonorrhea } \\
\text { [2008-2013] }\end{array}$ & $\begin{array}{c}\text { Gonorrhea } \\
\text { [2014-2019] }\end{array}$ & $\begin{array}{c}\text { Chlamydia } \\
\text { [2008-2013] }\end{array}$ & $\begin{array}{l}\text { Chlamydia } \\
\text { [2014-2019] }\end{array}$ & $\begin{array}{l}\text { P \& S } \\
\text { Syphilis } \\
{[2008-} \\
2013]\end{array}$ & $\begin{array}{c}\text { P \& S } \\
\text { Syphilis } \\
{[2014-2019]}\end{array}$ & $\begin{array}{l}\text { Participated } \\
\text { in Breast } \\
\text { Cancer } \\
\text { Screening } \\
{[2008-2013]}\end{array}$ & $\begin{array}{l}\text { Participated } \\
\text { in Breast } \\
\text { Cancer } \\
\text { Screening } \\
{[2014-2019]}\end{array}$ & $\begin{array}{c}\% \text { of Patient } \\
\text { Access to } \\
\text { Healthcare } \\
{[2008-2013]}\end{array}$ & $\begin{array}{c}\% \text { of } \\
\text { Patient } \\
\text { Access to } \\
\text { Healthcare } \\
{[2014-} \\
2019]\end{array}$ \\
\hline $\mathrm{N}$ & Valid & 6 & 6 & 6 & 6 & 6 & 6 & 6 & 6 & 6 & 6 \\
\hline Mean & & 9071.50 & 11321.67 & 28065.00 & 33641.00 & 533.50 & 718.17 & 411488.17 & 3220.67 & 18.38 & 21.43 \\
\hline Median & & 8998.50 & 11398.50 & 28379.50 & 33527.00 & 496.00 & 723.00 & 47510.50 & 3045.00 & 18.80 & 21.62 \\
\hline Mode & & $8669.00^{\mathrm{a}}$ & $8978.00^{\mathrm{a}}$ & $23485.00^{\mathrm{a}}$ & $30896.00^{\mathrm{a}}$ & $339.00^{\mathrm{a}}$ & $575.00^{\mathrm{a}}$ & $2435.00^{\mathrm{a}}$ & $2435.00^{\mathrm{a}}$ & $16.98^{\mathrm{a}}$ & $19.60^{\mathrm{a}}$ \\
\hline Std. Deviation & & 363.30 & 1596.18 & 2680.07 & 2287.39 & 161.29 & 88.23 & 598894.80 & 793.04 & 0.99 & 1.19 \\
\hline Variance & & 131985.90 & 2547784.26 & 7182794.00 & 5232137.20 & 26015.50 & 7784.57 & $\begin{array}{r}3586749759 \\
93.77\end{array}$ & 628917.07 & 0.98 & 1.41 \\
\hline Range & & 1049.00 & 4225.00 & 8157.00 & 5253.00 & 388.00 & 245.00 & 1185810.00 & 1747.00 & 2.42 & 3.08 \\
\hline Minimum & & 8669.00 & 8978.00 & 23485.00 & 30896.00 & 339.00 & 575.00 & 2435.00 & 2435.00 & 16.98 & 19.60 \\
\hline Maximum & & 9718.00 & 13203.00 & 31642.00 & 36149.00 & 727.00 & 820.00 & 1188245.00 & 4182.00 & 19.40 & 22.68 \\
\hline \multirow{3}{*}{ Percentiles } & 25 & 8822.00 & 9950.00 & 26386.00 & 31519.25 & 402.00 & 653.00 & 2892.50 & 2435.00 & 17.22 & 20.35 \\
\hline & 50 & 8998.50 & 11398.50 & 28379.50 & 33527.00 & 496.00 & 723.00 & 47510.50 & 3045.00 & 18.80 & 21.62 \\
\hline & 75 & 9308.50 & 12809.25 & 29773.75 & 36052.25 & 721.75 & 796.75 & 1182198.50 & 4182.00 & 19.09 & 22.52 \\
\hline
\end{tabular}

a. Multiple modes exist. The smallest value is shown

Source: Results from SPSS 20.0

In all 12-sample size were used for the data analysis. For the purposes of grouping the data into two, such as: before clinic closure (2008-2013), and during/after clinic closure (2014-2019). Five (5) public health unit preventive practices data were used for the analysis: (1) Gonorrhea infection data, (2) Chlamydia infection data, (3) Syphilis infection data, (4) Breast Cancer Screening data, and (5) Access to healthcare data.

\section{Summary Statistics of Gonorrhea Infection Data During/After the Closure of the Public Health Clinic [2008-2013]}

For the case of Gonorrhea infection rate before the closure of the public health clinics and policies consolidations [2008-2013], it was observed in the Table 1 that the average or mean Gonorrhea infection rate 2008 and 2013 is 9071.50 per every 100,000 . The median value (or $50^{\text {th }}$ percentile, or $2^{\text {nd }}$ quartile) of the Gonorrhea infection rate between 2008 and 2013 is 8998.50 per every 100,000 screening. The standard deviation associated with the Gonorrhea infection rate between 2008 and 2013 is 363.30 per every 100,000 screening. Additionally, the range associated with the Gonorrhea infection rate between 2008 and 2013 is 1049.00 per every 100,000 screening. This implies that the difference between the maximum Gonorrhea infection rate ( 9718.00 per every $100,000 \mathrm{screening})$ and the minimum Gonorrhea infection rate ( 8669.00 per every 100,000 screening) between 2008 and 2013 is 1049.00 per every 100,000 screening. In terms of positions, about $25 \%$ of the Gonorrhea infection rate between 2008 and 2013 representing the $1^{\text {st }}$ quartile (or $25^{\text {th }}$ percentile) is less than or equal to 8822.00 per every 100,000 screening. For the case of the $75^{\text {th }}$ percentile or the $3^{\text {rd }}$ quartile; about $75 \%$ of the Gonorrhea infection rate between 2008 and 2013 is less than or equal to 9308.50 per every 100,000 screening.

Summary Statistics of Gonorrhea Infection Data before the Closure of the Public Health Clinic [2014-2019] In relation to the analysis of the Gonorrhea infection rate during/after the closure of the public health clinics and policies consolidations [2014-2019], it was also observed in the Table 1 that the average or mean Gonorrhea infection rate between 2014 and 2019 is 11321.67 per every 100, 000, which is greater than the average infection rate before the closure of the public health clinics. The median value (or $50^{\text {th }}$ percentile, or $2^{\text {nd }}$ quartile) of the Gonorrhea infection rate between 2014 and 2019 is 11398.50 per every 100,000 screening, which is also greater than the median infection rate value before the closure of the public health clinics. The standard deviation associated with the Gonorrhea infection rate between 2014 and 2019 is 1596.18 per every 100,000 screening. Additionally, the range associated with the Gonorrhea infection rate between 2014 and 2019 is 4225.00 per every 100,000 screening. This implies that the difference between the maximum Gonorrhea infection rate $(13,203.00$ per every 100,000 screening) and the minimum Gonorrhea infection rate ( 8978.00 per every $100,000 \mathrm{screening})$ between 2014 and 2019 is 4225.00 per every 100,000 screening. In terms of positions, about 25\% of the Gonorrhea 
infection rate between 2014 and 2019 representing the $1^{\text {st }}$ quartile (or $25^{\text {th }}$ percentile) is less than or equal to 9950.00 per every 100,000 screening. For the case of the $75^{\text {th }}$ percentile or the $3^{\text {rd }}$ quartile; about $75 \%$ of the Gonorrhea infection rate between 2014 and 2019 is less than or equal to 12809.25 per every 100,000 screening.

\section{Summary Statistics of Chlamydia Infection Data During/After the Closure of the Public Health Clinic [2008-2013]}

Regarding the analysis of Chlamydia infection rate before the closure of the public health clinics and policies consolidations [2008-2013], it was observed in the Table 1 that the average or mean Chlamydia infection rate 2008 and 2013 is $28,065.00$ per every 100,000 . The median value (or $50^{\text {th }}$ percentile, or $2^{\text {nd }}$ quartile) of the Chlamydia infection rate between 2008 and 2013 is 28379.50 per every 100,000 screening. The standard deviation associated with the Chlamydia infection rate between 2008 and 2013 is 2680.07 per every 100,000 screening. Additionally, the range associated with the Chlamydia infection rate between 2008 and 2013 is 8,157.00 per every 100,000 screening. This implies that the difference between the maximum Chlamydia infection rate $(31,642.00$ per every 100,000 screening) and the minimum Chlamydia infection rate $(23,485.00$ per every 100,000 screening) between 2008 and 2013 is 8,157.00 per every 100,000 screening. In terms of positions, about $25 \%$ of the Chlamydia infection rate between 2008 and 2013 representing the $1^{\text {st }}$ quartile (or $25^{\text {th }}$ percentile) is less than or equal to $26,386.00$ per every 100,000 screening. For the case of the $75^{\text {th }}$ percentile or the $3^{\text {rd }}$ quartile; about $75 \%$ of the Chlamydia infection rate between 2008 and 2013 is less than or equal to 29,773.75 per every 100,000 screening.

Summary Statistics of Chlamydia Infection Data before the Closure of the Public Health Clinic [2014-2019] For the case of Chlamydia infection rate during/after the closure of the public health clinics and policies consolidations [2014-2019], it was also observed in the Table 1 that the average or mean Chlamydia infection rate 2014 and 2019 is 33,641.00 per every 100, 000, which is greater than the average infection rate before the closure of the public health clinics. The median value (or $50^{\text {th }}$ percentile, or $2^{\text {nd }}$ quartile) of the Chlamydia infection rate between 2014 and 2019 is 33,527.00 per every 100,000 screening, which is also greater than the median infection rate value before the closure of the public health clinics. The standard deviation associated with the Chlamydia infection rate between 2014 and 2019 is 2287.39 per every 100,000 screening. Additionally, the range associated with the Chlamydia infection rate between 2014 and 2019 is 5, 253.00 per every 100,000 screening. This implies that the difference between the maximum Chlamydia infection rate $(36,149.00$ per every 100,000 screening) and the minimum Chlamydia infection rate (30,896.00 per every 100,000 screening) between 2014 and 2019 is 5, 253.00 per every 100,000 screening. In terms of positions, about $25 \%$ of the Chlamydia infection rate between 2014 and 2019 representing the $1^{\text {st }}$ quartile (or $25^{\text {th }}$ percentile) is less than or equal to $31,519.25$ per every 100,000 screening. For the case of the $75^{\text {th }}$ percentile or the $3^{\text {rd }}$ quartile; about $75 \%$ of the Chlamydia infection rate between 2014 and 2019 is less than or equal to $36,052.25$ per every 100,000 screening.

\section{Summary Statistics of Primary (P) and Secondary Syphilis Infection Data During/After the Closure of the Public Health Clinic [2008-2013]}

For the case of S\&P Syphilis infection rate before the closure of the public health clinics and policies consolidations [2008-2013], it was further observed in the Table 1 that the average or mean S\&P Syphilis infection rate 2008 and 2013 is 533.50 per every 100,000 . The median value (or $50^{\text {th }}$ percentile, or $2^{\text {nd }}$ quartile) of the $S \& P$ Syphilis infection rate between 2008 and 2013 is 496.00 per every 100,000 screening. The standard deviation associated with the S\&P Syphilis infection rate between 2008 and 2013 is 161.29 per every 100,000 screening. Additionally, the range associated with the S\&P Syphilis infection rate between 2008 and 2013 is 388.00 per every 100,000 screening. This implies that the difference between the maximum S\&P Syphilis infection rate (727.00 per every 100,000 screening) and the minimum S\&P Syphilis infection rate (339.00 per every 100,000 screening) between 2008 and 2013 is 388.00 per every 100,000 screening. In terms of positions, about $25 \%$ of the S\&P Syphilis infection rate between 2008 and 2013 representing the $1^{\text {st }}$ quartile (or $25^{\text {th }}$ percentile) is less than or equal to 402.00 per every 100,000 screening. For the case of the $75^{\text {th }}$ percentile or the $3^{\text {rd }}$ quartile; about $75 \%$ of the $S \& P$ Syphilis infection rate between 2008 and 2013 is less than or equal to 721.75 per every 100,000 screening.

\section{Summary Statistics of Primary (P) and Secondary (S) Syphilis Infection Data before the Closure of the Public Health Clinic [2014-2019]}

In relation to the analysis of the S\&P Syphilis infection rate during/after the closure of the public health clinics and policies consolidations [2014-2019], it was also observed in the Table 1 that the average or mean S\&P Syphilis infection rate 2014 and 2019 is 718.17 per every 100, 000, which is greater than the average infection rate before the closure of the public health clinics. The median value (or $50^{\text {th }}$ percentile, or $2^{\text {nd }}$ quartile) of the S\&P Syphilis infection rate between 2014 and 2019 is 723.00 per every 100,000 screening, which is also greater than the median infection rate value before the closure of the public health clinics. The standard deviation associated with the S\&P Syphilis infection rate between 2014 and 2019 is 88.23 per every 100,000 screening. Additionally, the range 
associated with the S\&P Syphilis infection rate between 2014 and 2019 is 245.00 per every 100,000 screening. This implies that the difference between the maximum S\&P Syphilis infection rate ( 820.00 per every 100,000 screening) and the minimum S\&P Syphilis infection rate (575.00 per every 100,000 screening) between 2014 and 2019 is 245.00 per every 100,000 screening. In terms of positions, about $25 \%$ of the S\&P Syphilis infection rate between 2014 and 2019 representing the $1^{\text {st }}$ quartile (or $25^{\text {th }}$ percentile) is less than or equal to 653.00 per every 100,000 screening. For the case of the $75^{\text {th }}$ percentile or the $3^{\text {rd }}$ quartile; about $75 \%$ of the S\&P Syphilis infection rate between 2014 and 2019 is less than or equal to 796.75 per every 100,000 screening.

\section{Summary Statistics of Breast Cancer Participation Screening Data Before the Closure of the Public Health Clinic [2008-2013]}

For the purposes of analysis of the number of breast cancer screening participation before the closure of the public health clinics and policies consolidations [2008-2013], it was further observed in the Table 1 that the average or mean number of breast cancer screening participation between 2008 and 2013 is $411,488.17$, which is greater than the average number of screening participation during/after the closure of public health clinics. The median value (or $50^{\text {th }}$ percentile, or $2^{\text {nd }}$ quartile) of the number of breast cancer screening participation between 2008 and 2013 is 47510.50 , which also greater than the median number of screening participation during/after the closure of public health clinics. The standard deviation associated with the number of breast cancer screening participation between 2008 and 2013 is 598,894.80. Additionally, the range associated with the number of breast cancer screening participation between 2008 and 2013 is 1,185,810.00. This implies that the difference between the maximum number of breast cancer screening participation $(1,188,245.00)$ and the minimum number of breast cancer screening participation $(2,435.00)$ between 2008 and 2013 is $1,185,810.00$. In terms of positions, about $25 \%$ of the number of breast cancer screening participation between 2008 and 2013 representing the $1^{\text {st }}$ quartile (or $25^{\text {th }}$ percentile) is less than or equal to $2,892.50$. For the case of the $75^{\text {th }}$ percentile or the $3^{\text {rd }}$ quartile; about $75 \%$ of the number of breast cancer screening participation between 2008 and 2013 is less than or equal to $1,182,198.50$

\section{Summary Statistics of Breast Cancer Participation Screening Data During/After the Closure of the Public Health Clinic [2014-2019]}

With regards to the number of breast cancer screening participation during/after the closure of the public health clinics and policies consolidations [2014-2019], it was further observed in the Table 1 that the average or mean number of breast cancer screening participation between 2014 and 2019 is $3,220.67$. The median value (or $50^{\text {th }}$ percentile, or $2^{\text {nd }}$ quartile) of the number of breast cancer screening participation between 2014 and 2019 is 3,045.00. The standard deviation associated with the number of breast cancer screening participation between 2014 and 2019 is 793.04. Additionally, the range associated with the number of breast cancer screening participation between 2014 and 2019 is $1,747.00$. This implies that the difference between the maximum number of breast cancer screening participation $(4,182.00)$ and the minimum number of breast cancer screening participation $(2,435.00)$ between 2014 and 2019 is $1,747.00$. In terms of positions, about $25 \%$ of the number of breast cancer screening participation between 2014 and 2019 representing the $1^{\text {st }}$ quartile (or $25^{\text {th }}$ percentile) is less than or equal to $2,435.00$. For the case of the $75^{\text {th }}$ percentile or the $3^{\text {rd }}$ quartile; about $75 \%$ of the number of breast cancer screening participation between 2014 and 2019 is less than or equal to 4,182.00.

\section{Summary Statistics of Percentage of Patients Not Able to See a Doctor [Access to Healthcare] Data Before the Closure of the Public Health Clinic [2008-2013]}

Regarding the percentage of patients not able to see a doctor (access to healthcare) before the closure of the public health clinics and policies consolidations [2008-2013], it was further observed in the Table 1 that the average percentage of patients not able to see a doctor (access to healthcare) between 2008 and 2013 is $18.38 \%$, which is better than the average percentage of patients not able to see a doctor (access to healthcare) during/after the closure of public health clinics (with a high average value of $21.43 \%$ ). The median value (or $50^{\text {th }}$ percentile, or $2^{\text {nd }}$ quartile) of the percentage of patients not able to see a doctor (access to healthcare) between 2008 and 2013 is $18.80 \%$, which is also better than the average percentage of patients not able to see a doctor (access to healthcare) during/after the closure of public health clinics (with a high average value of $21.62 \%$ ). The standard deviation associated with the percentage of patients not able to see a doctor (access to healthcare) between 2008 and 2013 is $0.99 \%$. Additionally, the range associated with the percentage of patients not able to see a doctor (access to healthcare) between 2008 and 2013 is $2.42 \%$. This implies that the difference between the maximum percentage of patients not able to see a doctor (access to healthcare) (19.40\%) and the minimum percentage of patients not able to see a doctor (access to healthcare) (2,435.00) between 2008 and 2013 is $16.98 \%$. In terms of positions, about $25 \%$ of the percentage of patients not able to see a doctor (access to healthcare) between 2008 and 2013 representing the $1^{\text {st }}$ quartile (or $25^{\text {th }}$ percentile) is less than or equal to $17.22 \%$. For the case of the $75^{\text {th }}$ percentile or the $3^{\text {rd }}$ quartile; about $75 \%$ of the percentage of patients not able to see a doctor (access to healthcare) between 
2008 and 2013 is less than or equal to $19.09 \%$.

Summary Statistics of Percentage of Patients Not Able to See a Doctor [Access to Healthcare] Data During/After the Closure of the Public Health Clinic [2014-2019]

In relation to the percentage of patients not able to see a doctor (access to healthcare) during/after the closure of the public health clinics and policies consolidations [2014-2019], it was further observed in the Table 1 that the average percentage of patients not able to see a doctor (access to healthcare) between 2014 and 2019 is $21.43 \%$. The median value (or $50^{\text {th }}$ percentile, or $2^{\text {nd }}$ quartile) of the percentage of patients not able to see a doctor (access to healthcare) between 2014 and 2019 is $21.62 \%$. The standard deviation associated with the percentage of patients not able to see a doctor (access to healthcare) between 2014 and 2019 is 1.19\%. Additionally, the range associated with the percentage of patients not able to see a doctor (access to healthcare) between 2014 and 2019 is 3.08\%. This implies that the difference between the maximum percentage of patients not able to see a doctor (access to healthcare) $(22.68 \%$ ) and the minimum percentage of patients not able to see a doctor (access to healthcare) (19.60) between 2014 and 2019 is $3.08 \%$. In terms of positions, about $25 \%$ of the percentage of patients not able to see a doctor (access to healthcare) between 2014 and 2019 representing the $1^{\text {st }}$ quartile (or $25^{\text {th }}$ percentile) is less than or equal to $20.35 \%$. For the case of the $75^{\text {th }}$ percentile or the $3^{\text {rd }}$ quartile; about $75 \%$ of the percentage of patients not able to see a doctor (access to healthcare) between 2014 and 2019 is less than or equal to $22.52 \%$.

Is there any difference in the public health units' data on breast cancer screening, STD screening, and access to healthcare based on clinic closure and consolidation policies?

Table 2: Difference-In-Mean Paired T-test Analysis

\begin{tabular}{|l|l|l|l|}
\hline Difference in Means & $\begin{array}{l}\text { Mean Difference } \\
\text { Value }\end{array}$ & $\begin{array}{l}\text { T- } \\
\text { value }\end{array}$ & $\begin{array}{l}\text { P- } \\
\text { values }\end{array}$ \\
\hline Gonorrhea [2008-2013]- Gonorrhea [2014-2019] & $-2250.17^{* *}$ & -2.89 & 0.034 \\
\hline Chlamydia [2008-2013] - Chlamydia [2014-2019] & $-5576.00^{* *}$ & -5.31 & 0.003 \\
\hline P \& S Syphilis [2008-2013] - P \& S Syphilis [2014-2019] & -184.67 & -1.93 & 0.111 \\
\hline $\begin{array}{l}\text { Participated in Breast Cancer Screening [2008-2013] - Participated in } \\
\text { Breast Cancer Screening [2014-2019] }\end{array}$ & $408267.50^{* *}$ & 2.67 & 0.041 \\
\hline $\begin{array}{l}\text { \% of Patient Access to Healthcare [2008-2013] - \% of Patient Access } \\
\text { to Healthcare [2014-2019] }\end{array}$ & $-3.06^{* * *}$ & -6.11 & 0.002 \\
\hline
\end{tabular}

Note: $\mathrm{p}$-value $<0.01 ; 0.01<\mathrm{p}$-value $<0.05 ; 0.05<\mathrm{p}$-value $<0.10 ; \mathrm{p}$-value $>0.10$. The mean difference value of the paired $\mathrm{t}$ tests techniques is evaluated by $* * *, * * *$ denoting statistical significance levels at $10 \%, 5 \%$, and $1 \%$ respectively.

Source: Results from SPSS 20.0

Table 2 presents the hypothesis testing analysis of a paired sample t-test to examine whether there is a statistical difference in the public health units' data on breast cancer screening, STD screening, and access to healthcare based on the periods before and during/after the clinic closure and consolidation policies (Affordable health care policy). For the case of the first paired analysis regarding the difference in overall Gonorrhea infection rate between the period before the public health clinic closure [2008-2013] and the period during/after the public health clinic closures [2014-2019], there is a statistical difference of $-2,250.17$ infections per every 100,000 in the means of Gonorrhea infection rate across Louisiana state parishes from 2008 to 2019. The difference in infection rate of Gonorrhea is statistically significant at 5\% (0.05) alpha-levels with a paired t-value of 2.89 and an associated $\mathrm{p}$-value of 0.034 . There exists a statistically significant difference in the Gonorrhea infection rate before [20082013] and during/after [2014-2019] the public health clinic closures and consolidation policies since the associated $\mathrm{p}$-value of 0.034 is less than 0.05 . This implies that on average the closure of the public health clinics and the consolidation of healthcare policies (i.e. such as Affordable healthcare) has caused the discrepancies (or gap) in the Gonorrhea infection rate by 2250.17 infections per every 100,000 screening.

In relation to the difference in means analysis of Chlamydia infection rate between the period before the public health clinic closure [2008-2013] and the period during/after the public health clinic closures [2014-2019], Table 2 further reveals that there is a statistical difference in Chlamydia infection of -5576.00 infections per every 100,000 across Louisiana state parishes from 2008 to 2019. The difference in infection rate of Chlamydia is statistically significant at 5\% (0.05) alpha-levels with a paired t-value of 2.89 and an associated p-value of 0.034 (i.e. since the associated p-value of 0.034 is less than 0.05 ).This implies that on average the closure of the public health clinics and the consolidation of healthcare policies (i.e. such as Affordable healthcare) has caused the 
increased in the average Chlamydia infection rate by $-5,576.00$ infections per every 100,000 screening.

With regards to the difference in means analysis of the number of breast cancer screening participation between the period before the public health clinic closure [2008-2013] and the period during/after the public health clinic closures [2014-2019], Table 2 further reveals that there is a statistical difference in the number of breast cancer screening participation of 408,267 participants across the Louisiana state parishes from 2008 to 2019 . The difference in the number of breast cancer screening participation is statistically significant at $5 \%(0.05)$ alphalevels with a paired t-value of 2.67 and an associated p-value of 0.041 (i.e. since the associated p-value of 0.041 is less than 0.05). This implies that on average the period before the closure of the public health clinics and the consolidation of healthcare policies (i.e. such as Affordable healthcare) did better in serving more participants of breast cancer screening than the period during/after the closure of the public health clinics and the consolidation of healthcare policies (i.e. such as Affordable healthcare). This particular difference may be attributed to the fact that there were more available testing and screening centers for breast cancer screening before the implementation of the public health clinics closures and consolidation policies and therefore, led to the increase in participation between 2008 and 2013.

Above all, Table 2 also discusses the difference in means analysis of the percentage of patients not able to see a doctor (access to healthcare) between the period before the public health clinic closure [2008-2013] and the period during/after the public health clinic closures [2014-2019]. According to the data, it was observed that there is a statistical difference in the percentage of patients not able to see a doctor (access to healthcare) of $-3.06 \%$ across the Louisiana state parishes from 2008 to 2019. The difference in the percentage of patients not able to see a doctor (access to healthcare) is statistically significant at $1 \%(0.01)$ and 5\% (0.05) alpha-levels with a paired tvalue of -6.11 and an associated p-value of 0.002 (i.e. since the associated p-value of 0.002 is less than 0.01 and 0.05 , respectively). This implies that on average the period before the closure of the public health clinics and the consolidation of healthcare policies (i.e. such as Affordable healthcare) did better in minimizing the percentage of patients not able to see a doctor (access to healthcare) than the period during/after the closure of the public health clinics and the consolidation of healthcare policies (i.e. such as Affordable healthcare).

\section{CONCLUSION AND POLICY IMPLICATIONS}

In conclusion, the analysis of the study finds that the average Gonorrhea infection rate, Chlamydia infection rate, and P\&S Syphilis infection rate between 2014 and 2019 is greater than the average infection rate before the closure of the public health clinics (2008 and 2013). Above all, the study establishes that there is a strong evidence of significant difference in the following: (a) access to healthcare, (b) Sexually-Transmitted Disease (STD) Screening preventative practices, and (c) the participation of Breast Cancer Screening preventative practices resulting from the different periods of policy implementation in relation to public health clinic closures. Specifically, the study establishes a strong evidence of significant difference in access to healthcare (i.e. those who do not get access to healthcare to see a doctor) resulting from the different periods of policy implementation in relation to public health clinic closures. The study further establishes a strong evidence of significant difference in the Chlamydia infection rates (with a p-value of $0.003<0.01$ ) as a measure of the Sexually-Transmitted Disease (STD) Screening preventative practices impact resulting from the different periods of policy implementation in relation to public health clinic closures. As policy implications, the study suggested the following: (a) That the policymakers and the lawmakers should enact regulations/policies to encourage and promote the use of protective tools or family planning protective tools or techniques such as the use of condom to control the spread of the sexually transmitted diseases (STDs). Such protective items or tools for sexual intercourse need to be free or highly subsidize by the federal, state, and local governments to ensure easy accessibility and encourage usage to help curb the spread of STDs. And (b) That the federal governments, state governors and local governments should subsidize the cancer preventive screening or expand the Medicaid and Medicare coverage to cover the treatment and screening processes of cancer related cases. Also, the governments can make health insurance a social right for its citizen to achieve a universal coverage in order to safeguard the health of the citizen for easy prevention of STDs, Cancer and also ensure easy access to health care facilities.

\section{REFERENCES}

Affordable Care Act Medicaid expansion. (2018). Retrieved November 13, 2018, from http://www.ncsl.org/research/health/affordable-care-act-expansion.aspx

American Presidency Project. (1996). American Presidency Project: William J. Clinton Statement on Signing the Health Centers Consolidation Act of 1996.

Andulis D.P. (2007). The changing landscape of hospital capacity in large cities and suburbs. Journal of Urban Health, 400-414.

Birkland, T. (2011). An Introduction to the Policy Process: theories, concepts, and models of public policy making. $3^{\text {rd }}$ edition. Routledge, Taylor \& Francis Group.

Buchmuelier, J.W. (2006). How far to the hospital? The effect of hospital closures on access to care. Journal of 
Health Economics.

Cantor, B.S. (2010). Aiming Higher: Results from a State Scorecard on Health Systems Performance.

CDC MMWR (1995) Impact of Closure of Sexually Transmitted Disease Clinic on Public Health Surveillance of Sexually Transmitted Diseases. DC.

Center for Medicare and Medicaid Services, Office of the Actuary, National Health Statistics Group. (2010). Healthcare Expenditure Analysis. National Health Care Expenditure Data.

Centers for Medicare and Medicare Services. (2012). Medicare and Medicare Services. CMS. Retrieved from Centers for Medicare and Medicare Services.

Cunningham, N.B. (2006). Results from a State Scorecard on Health Systems Performance. NASHP

Currie, R. (1998) Distance to Hospitals and Children's Access to Care: Is Being Close Better, and for Whom? The National Bureau of Economic Research.

DC Goodman, E.F. (1997). The distance of community medical care and the likelihood of hospitalization: is loser always better? American Journal of Public Health, Vol. 87, Issue 7 1144-1150.

Deal LW, S.P. (1998). Medicaid managed care and children: an overview. Future Child, 93-104. DHH (2005). Making Medicaid Better FAQ's'.

DHH (2015/2016). Louisiana Annual Medicaid Report.

Eddy. (1997). Balancing cost and quality in fee for service versus managed care. Health Affairs, 162-173.

Grubar, J. (2016). Public Finance and Public Policy. $5^{\text {th }}$ edition. Worth Publishers: A Macmillan Education Imprint New York, pp. 3-23.

Havlovic, B.V. (1998). Coping with Downsizing and Job Loss. Canadian Journal of Administrative Science, $322-$ 332.

Henry J. Kaiser-Family Foundation. (2010). Focus on Health Reform: Health Reform Implementation Timeline.

Hadley, J. (2003). Sicker and poorer: The consequences of being uninsured. Medical Care Research and Review, 60 (2, Suppl): 3S-75S. doi:10.1177/1077558703254101

Institute of Medicine. (2009). America's uninsured crisis: Consequences for health and health care. Washington, $D C$ : National Academies Press.

Isaac, S., \& Michael, W. B. (1981). Handbook in research and evaluation (2nd ed.). San Diego, CA: EDITS.

Jonk, Y. C.; Call, K. T., Cutting; A. H., O'Conner; H. Bansiya, V.; \& Harrison, K. (2005). Health care coverage and access to care: The status of Minnesota's veterans. Medical Care, 43(8), 769-774. Retrieved from http://www.jstor.org/stable/3768294

Jlida C.G.; Hyndman, C.D. (2000). Differential effects on socioeconomic groups of modeling the location of mammography screening clinics using Geographic Information Systems. Australian and New Zealand Journal of Public Health, volume 24, issue 3, pages 281-286.

Kaiser Family Foundation and Health Research and Educational Trust. (2009). Employer Health Benefits 2009 Annual Survey.

Kaiser Commission on Medicaid and the Uninsured. (2012). The Uninsured: A primer: Key facts About Americans without health insurance. Retrieved from https://kaiserfamilyfoundation.files.wordpress.com/2013/01/745108.pdf

Kaiser Family Foundation. (2008). Eliminating racial/ethnic disparities in health care: What are the options? Retrieved August, 2017, from 152 https:/www.kff.org/disparities-policy/issue-brief/eliminatingracialethnicdisparities-in-health-care-what/

Kaiser Family Foundation. (2009). Low-income adults under age 65-many are poor, Sick, and uninsured. Policy Brief, Publication \#7914 Retrieved from http://www.kff.org/healthreform/upload/7914.pdf

Kaiser Family Foundation. (2011). Health insurance coverage of women 19-64, states (2010-2011). Retrieved from http://www.kff.org/other/state-indicator/nonelderlyadult-women/

Kaiser Family Foundation. (2011). The uninsured: A primer, key facts about Americans without health insurance. Washington, DC: The Kaiser Commission on Medicaid and the Uninsured.

Kaluzny, H.A. (1983). Hospital Closure: A review of Current Proposed Research. Health Services Research.

LA Department of Hospitals Bureau of Health Services Financing. (2010). Declaration of Emergency. LA Department of Hospitals Bureau of Health Services Financing.

Laswell, H. (1936). Politics: Who Gets What, When, How. Britannica. https://www.britannica.com/topic/PoliticsWho-Gets-What-When-How

Larson, J.S. (1980). Why Government Programs Fail: Improving Policy Implementation, Greenwood Pub Group. Lindrooth, S.A. (2003). The Effect of Urban Hospital closure on Markets. Journal of Health Economics, 691-712.

Los Angeles Department of Health Services Acute Communicable Disease Control. (1995). Clinic Closure Impact: Cross-Sectional Survey Report. Los Angeles.

Louisiana State University Public Policy Research Lab. (2009). Health Insurance Survey. Louisiana State University Public Policy Research Lab Baton Rouge.

Marmor T,O.J. (1998). Rethinking Medicare Reform. Health Affairs, 52-60. 
Mayer, K.S.(1987). Patterns of Rural Hospital Closure in the United States. Social Science \& Medicine, 327-334.

McDonald, M., \& Hertz, R. (2008). A profile of uninsured persons in the United States. New York, NY: Pfizer.

McKay, C. (1995). Access implications of Rural Hospital Closures and Conversions. Hospital Service Administration, 227-246.

M.E. Sharpe. Patient Protection and Affordable Care Act, Public Law No. 111-148, Section 3502, 124 Stat. 119,124

Medical CRS Report. (2018). The Federal Assistance Percentage (FMAP). Medical CRS Report.

Menard, S. (1997). Applied logistic regression analysis (2nd ed., Vol. 106, Paper series on quantitative applications in the social sciences). Thousand Oaks, CA: Sage Publication.

Mesch,M.P.(1999). The effects of Hospital Closure on Mental Health Workers. Journal of Behavioral Health Services and Research, 305-317.

Mitchell JM, G. D. (2008). Health supervision visits among SSI eligible children in the D.C. Medical program.

Mosser, G., MD, Karp, M., MBA, \& Rabson, B. G., MPH. (2006, August 1). Regional coalitions for healthcare improvement: Definition, lessons, and prospects. Retrieved January, 2015, from http://www.improvingchroniccare.org/downloads/nrhi.pdf

Munoz E, S.R. (1986). Source of Admission and Cost; Public Hospitals Face Financial Risk. American Journal of Public Health, 696-697.

Muss, L.G. (1995). Community Perceptions of Rural Hospital Closure. Journal of Community Health, 65-73.

Musumeci, M. (2012, August 1). A Guide to the Supreme Court's Decision on the ACA's Medicaid Expansion. Retrieved June, 2016, from https://www.kff.org/healthreform/issue-brief/a-guide-to-the-supreme-courtsdecision/

National Conference of State Legislatures. (2011, March). The Affordable Care Act: A brief summary. Retrieved October, 2018, from http://www.ncsl.org/research/health/the-affordable-care-act-brief-summary.aspx

National Quality Forum. (2011). Prevention EM Phase 1 Screening and Immunization Measures.

ObamaCareFacts.com. (2014, August 8). State health insurance exchange: State run exchanges. Retrieved February, 2017, from https://obamacarefacts.com/statehealth-insurance-exchange/

Patel, K., \& Rushefsky, M. E. (2006). Health care politics and policy in America (3rd ed.). Armonk, N.Y.:

Patient Protection and Affordable Care Act, Public Law No. 111-148, Section 3502, 124 Stat. 119,124.

Piore, P.a. (1977). Public expenditures and private control? Health Care Dilemmas in New York City. Milbank Memorial Fund Quarterly, pp.79-116.

Probst, S.H. (1990). Economic Impact of Hospital Closure on Small Rural Counties, 1984 to 1988. Journal of Rural Health, 375-390.

Robert Wood Johnson Foundation University of Wisconsin Population Health Institute. (2011). County Health Ranking.

Rosenblatt RA, A.C. (2006). Shortages of medical personnel at Community Health Centers: Implications for Planned Expansion. JAMA.

Rothman, D. J. (1993). A century of failure: Health care reform in America. Journal of Health Politics, Policy and Law, 18(2).

Ross, M., \& Hayes, C. (1986). Consolidated Omnibus Budget Reconciliation Act of 1985 (Vol. 49, No. 8, Publication). Retrieved August, 2013, from https://www.ssa.gov/policy/docs/ssb/v49n8/v49n8p22.pdf

Schuster CR,M.J.(2007). Partially capitated managed care versus FFS for Special Needs Children. Health Care Finance Review, 109-123.

Shepard. (1983). Estimating the Effects of Hospital Closure on Area wide Inpatient Hospital Cost: A Preliminary Model and Application. Health Services Research.

Smith, J. C., \& Medalia, C. (2014, September). Health Insurance Coverage in the United States: 2013 (United States, United States Census Bureau). Retrieved August, 2017, from https://www.nber.org/cps/hi/2014redesign/p60-250.pdf

Sohn, H. (2016). Racial and ethnic disparities in health insurance coverage: Dynamics of gaining and losing coverage over the life-course. Population Research and Policy Review, 36(2), 181-201. doi:10.1007/s11113016-9416-y

The Lewin Group. (2006). Medicaid upper payment Limit Policies: Overcoming a Barrier to Managed Care Expansion. Medicaid Health Plans of America.

The Johns Hopkins University, \& Weiner, J. P., DrPH. (2008). Health policy and the delivery of health care: Introduction and private health plan case study. Lecture. Retrieved August, 2014, from http://ocw.jhsph.edu/courses/IntroHealthPolicy/PDFs/IHP_lec7_weiner.pdf

Trust for America's Health. (2009). Shortchanging America's Health: A State by State Look at How Federal Public Health Dollars are Spent.

United Health Foundation. (2010). America's Health Rankings. United Health Foundation

United States Congress UMTALA Act. (1986). 42 U S C 1395dd EMTALA ACT. 
Urban Institute and Kaiser Commission on Medicaid and the Uninsured. (2009/2010). Uninsured Estimates based on Census Bureau Population Surveys.

Urban Institute. (2010). Kaiser Commission on Medicaid and the Uninsured. Urban Institute.

Waitzkin (2005). The History and Contradictions of the Health Care Safety Net.

Whiteis D, S.J. (1978). The Proprietarization of Health Care and the Underdevelopment of the Public Sector. International Journal of Health Services. 47-64.

Williams, H.P. (1992). Profits, Community Role and Hospital Closure: An Urban and Rural Analysis. Medical Care, 174

Williams, W. (1980). Review of The Implementation Perspective a Guide for Managing Social Service Delivery Programs. University of California Press.

Williams, D. R., Mohammed, S.A., Leavell, J., \& Collins, C. (2010). Race, socioeconomic status, and health: complexities, ongoing challenges, and research opportunities. The Biology of Disadvantage: Socioeconomic Status and Health. Annals of the New York Academy of Science. , 1186, 69-101. doi: 10.1111/j.17496632.2009.05339.x 